\title{
UAV - a useful tool for monitoring woodlands
}

\section{Abstract}

Unmanned aerial systems are in many countries one of the most dynamically developing branches of technology. They have also been recognized and are being utilized by scientists who find remote sensing indispensable in their work. Today, it is increasingly common to find research teams utilizing so-called drones in field research. Unmanned systems are becoming ever more important for environment monitoring by, on the one hand, providing data from inaccessible or remote areas, and, on the other hand, reducing the human costs required by traditional large field teams while also increasing the efficiency of the work. This paper presents the possibility of utilizing UAVs for image data collection in woodland areas.

Flights over Głuchów and an Arboretum were performed using two different UAVs (Mentor, AVI). The flights were made in 2010 in the middle of the growing season. Images were taken with Sigma DP2 digital cameras in four spectral channels: R (red), G (green), B (blue) and IR (infrared). Images were saved in 8-bit. The Głuchów forest complex is located in the Głuchów forest district, which forms a part of the Rogów forest division. From the administrative viewpoint, the forest division is located in the Łódzkie province, Skierniewicki Poviat. The Arboretum is a park with a collection of trees and shrubs from different regions of the world. The area is characterized by a high variability of species and trees of varying heights. It is located in the Łódzkie province, Skierniewicki Poviat.

Keywords

$\mathrm{UAV} \cdot$ woodland monitoring $\bullet$ image data

(c) University of Warsaw - Faculty of Geography and Regional Studies
Anna Zmarz

Department of Geoinformation and Remote Sensing Faculty of Geography and Regional Studies University of Warsaw

e-mail: azmarz@uw.edu.pl

\section{Introduction}

In recent years it has been possible in practical terms to use unmanned aerial vehicles (UAVs) for obtaining images, orthophotos and 3D, which are useful in various fields. The construction of unmanned flying platforms and data collecting systems is the subject of many research projects all over the world (Merino et al. 2006; Grenzdörffer et al. 2008; Eisenbeiss 2008; Laliberte et al. 2010; Aber et al. 2010).

The main applications of such devices are related to the widely-understood environmental monitoring, archaeological site archiving, monitoring of crops, erosion of ravines, gorges, soil, documentation of backwaters, and also data gathering for forestry and remote areas such as the Arctic or Antarctica.

The UAVs are equipped with sensors to record data, which are the tools for providing current information about the area. The advantages of UAVs include: mobility, easier to use compared to manned platforms, the possibility of obtaining data at short intervals, and relatively low operating costs. Small-size pictures taken with amateur digital cameras are becoming increasingly useful for scientists in many fields due to the fact that non-metric images can be calibrated to become metric data. Low-altitude photography appears less expensive and more achievable due to simpler logistics and lower technical complexity. The use of unmanned aerial vehicles in data gathering originated in the military field but is now also more common in the civilian field, especially in so-called 3D work (Dull, Dirty and Dangerous) (Koski et al. 2010; Goraj et al. 2010; Zmarz 2011; Solb \& Storvold 2011).

\section{Unmanned platforms}

The design of the UAV is dependent on the task to be carried out. The main differences concern size, weight (Tab.1, Fig. 1), type of engine (gasoline engine or electric), and the control system all of which affect the range, load and flight time.

A complete UAV system is equipped with: an autonomic control system (i.e. the autopilot), which allows for accurate execution of the flight plan (by maintaining proper heading, altitude and turns); and a ground-control station that allows for communication with the platform in flight via a radio modem and is used to design the flight path and for continuous monitoring of the flight parameters. Additionally, the unmanned platforms may be equipped with parachutes, allowing them to perform a safe emergency landing. Depending on the UAV's size and weight, the take-off may be performed ,by hand', from a launcher or using a runway. The landing procedure is also dependent on the physical characteristics of the UAV and may use a rather small area, like 
Table 1. Classification of UAVs according to weight by Arjomandi 2006 (slightly modified)

\begin{tabular}{|c|c|c|}
\hline Specification & Weight [kg] & Type UAV \\
\hline Very heavy & $>2000$ & Global Hawk \\
\hline Heavy & $200-2000$ & Outrider \\
\hline Average & $50-200$ & Phoenix \\
\hline Light & $5-50$ & AVI \\
\hline Very light & $<5$ & Mentor \\
\hline
\end{tabular}
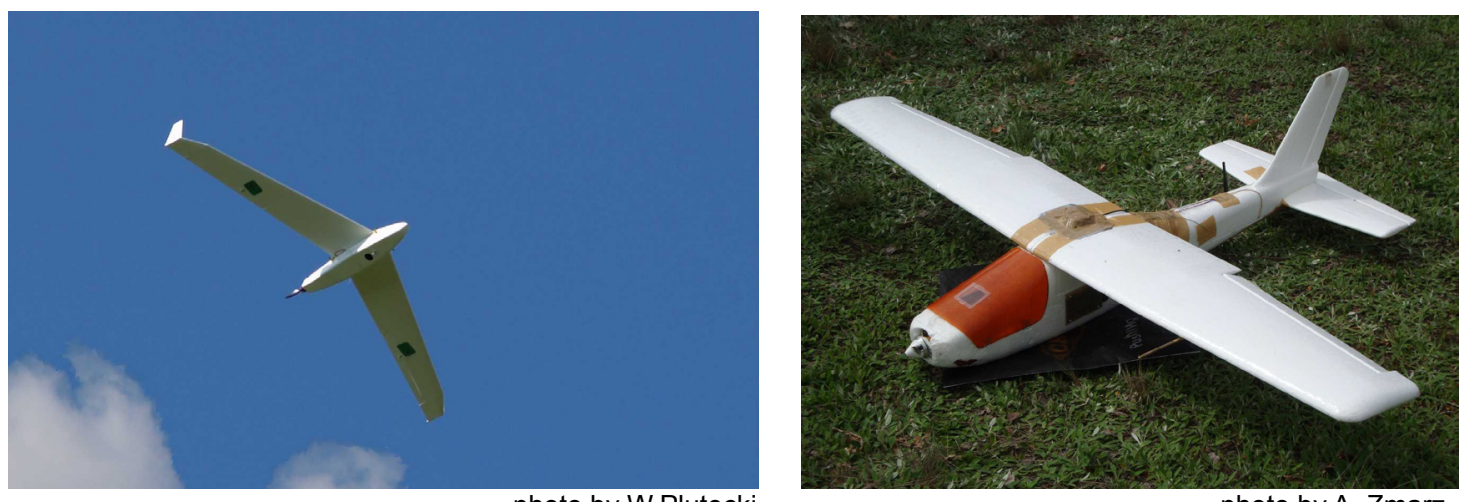

photo by W.Plutecki

photo by A. Zmarz

Figure 1. Two types of UAVs (from left: Nietoperz and Mentor with an automatic control system MP 2128)
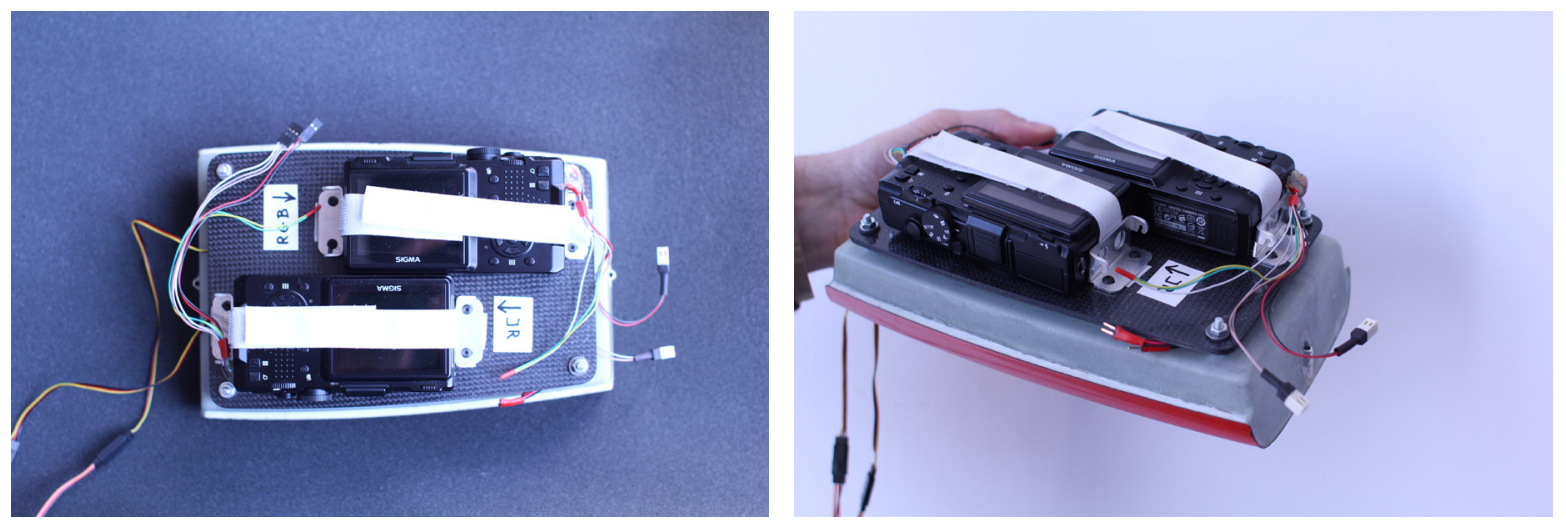

Figure 2. Container with two cameras to record RGB and IR (photo by A. Zmarz)

a stretch of a level meadow or a man-made landing strip. In especially difficult areas special nets are deployed to catch the UAV.

We are seeing the development of new aerial platforms that utilize solar-panels installed in the airframe. The on-board equipment is able to provide images that are equal, in many respects, to the ones gained from satellite systems. Stratospheric UAVs have been developed, designed for continuous data transmissions.

\section{Flight over the Głuchów area}

The flights over the Głuchów research area were performed using the AVI-1 airframe, designed to take aerial photos. The Głuchów forest complex is located in the Głuchów forest district, which forms part of the Rogów forest division. From the administrative viewpoint, the forest division is located in the Łódzkie province, Skierniewicki Poviat.

AVI-1 (Tab. 2) is a high-wing monoplane of composite construction powered by an electric engine (manufactured by the Taxus SI Company from Warsaw). The lower section of the fuselage holds a swappable photographic compartment, equipped with two compact photographic cameras of Sigma DP2 type (Fig. 2, 3). One of the cameras takes photos in natural RGB colours, the second one takes photos in near infra-red. The airframe is controlled using an automatic control system: MicroPilot MP2128; during take-off and landing the control system is assisted by a Remote Control (RC) system. The installed Sigma DP2 photographic cameras and the fuselage of 


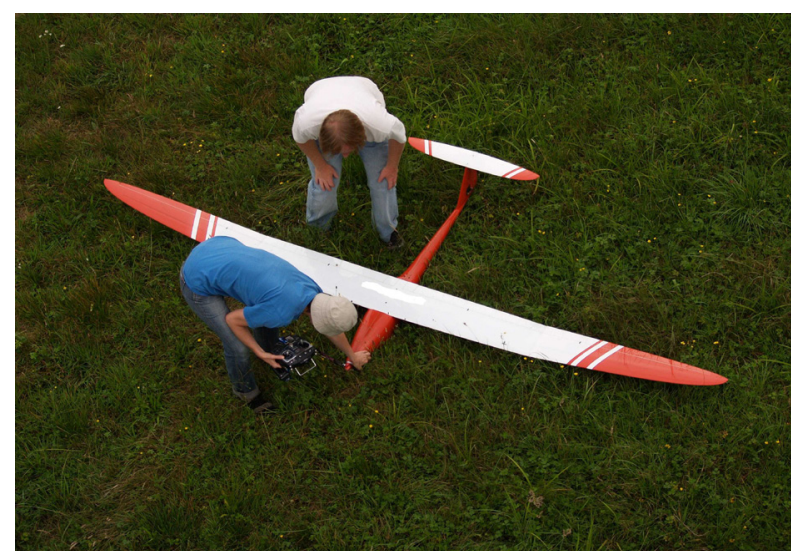

photo by W. Plutecki

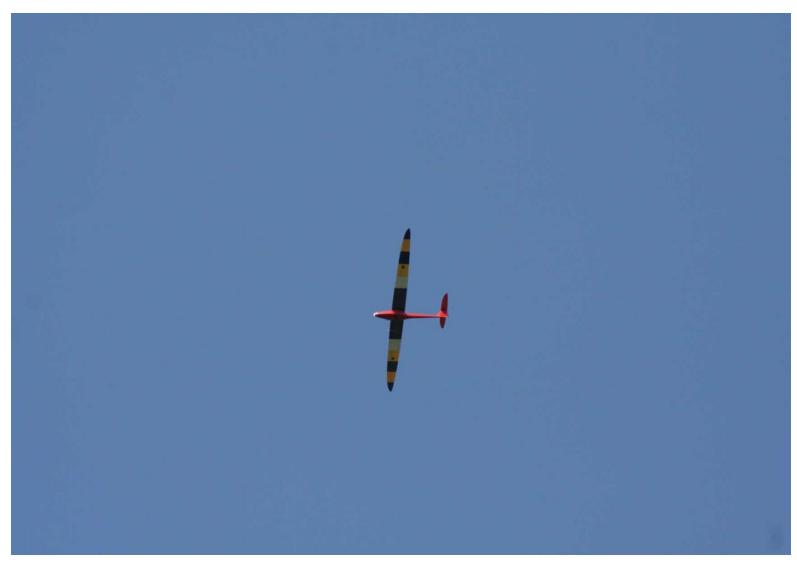

photo by A. Zmarz

Figure 3. AVI-1 prepared for flight and during flight, Głuchów 2010

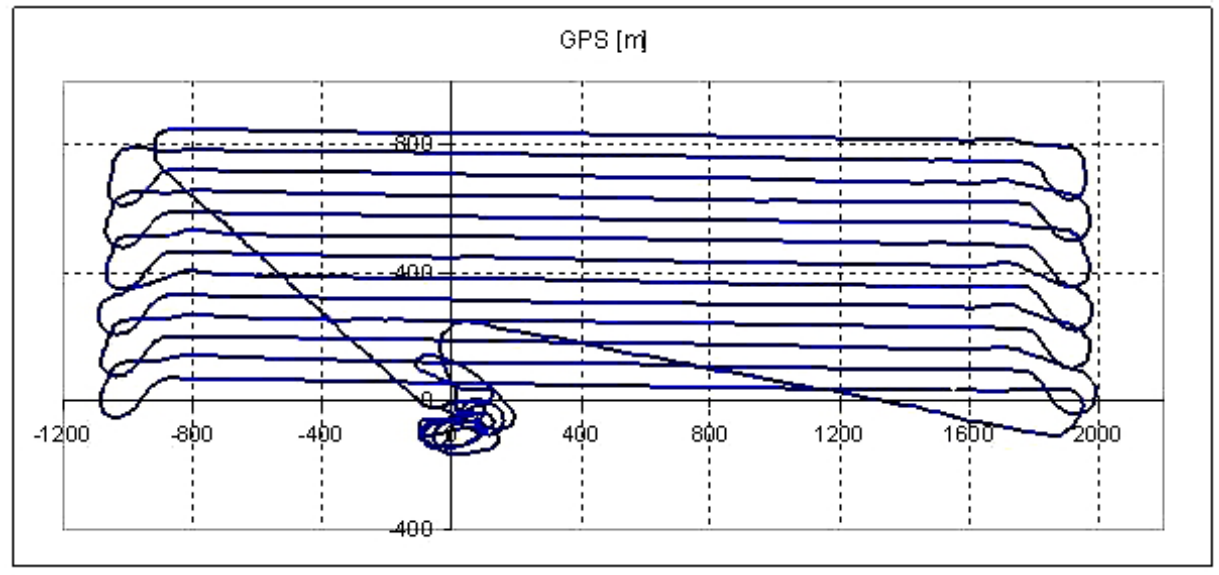

Figure 4. Flight recorded by the GPS during the AVI-1 flight over the Głuchów area

Table 2. Selected parameters of AVI-1

\begin{tabular}{|c|c|}
\hline Parameter & AVI-1 \\
\hline Wing span & $3.5[\mathrm{~m}]$ \\
\hline Weight in flight & $6.2[\mathrm{~kg}]$ \\
\hline Maximum flight time & $80[\mathrm{~min}]$ \\
\hline Maximum distance in flight & $90[\mathrm{~km}]$ \\
\hline
\end{tabular}

AVl-1 serve as an integral whole. The angles $\varphi, \omega, \mathrm{K}$, (phi, omega, kappa) are related to the heading of the airframe (expressing the instantaneous angular velocity of the rotating rigid body) and are registered and recorded by MP2128 during the flight.

As we can see in Fig. 4, which presents the path of the UAV, the working sections are parallel and in line with the flight path design. The creation of a flight plan is dependent on the size of the area, the atmospheric conditions on the day of the flight and the flight characteristics of the UAV. The actual flight path registered by the GPS and visible on the diagram shows a very high level of integration of the UAV control system and results from the AVI-1's airframe characteristics.

\section{Weather conditions}

The pass over Głuchów was performed in atmospheric conditions with no impact of thermal air movements and below the cloud threshold (Tab. 3). The flight resulted in so-called noshadow shots.

Atmospheric conditions have a significant impact on flight execution. When preparing a flight plan, the practice is to follow the weather forecast 2-3 days before the planned flight day, with the binding forecast being the one 24 hours before the planned flight day. However, it should be remembered that the weather on the planned flight day may be different from the forecast or may change unexpectedly. In such cases, it is necessary to introduce updates to the flight file interpreted by the MP2128 automatic control system in order to ensure safe and proper execution of the flight plan, as well as to ensure the gathering of photographic material that meets all the requirements.

The second factor affecting flight design is the size and shape of the area that is to be flown over. The target area size determines the manner in which the flight is executed and is related to the technical abilities of the UAV. Depending on the actual size of the target, the image-taking operation may be carried out in a single flight or can be divided into a number of related flights according to the target's shape and the UAV abilities (e.g. maximum flight length) as well as the safety rules (the UAV has to be visible to the operator and the RC pilot throughout the flight). 
Table 3. The total length of the flight and weather conditions for the Głuchów area

\begin{tabular}{|c|c|c|}
\hline Parameter & Value & Unit \\
\hline Size of the area & 284 & {$[\mathrm{ha}]$} \\
\hline Length of the flight route & 112.65 & - \\
\hline Wind direction & $\mathrm{N}$ & {$[\mathrm{km} / \mathrm{s}]$} \\
\hline Wind speed & $2-3$ & - \\
\hline Visibility & sky overcast & {$\left[{ }^{\circ} \mathrm{C}\right]$} \\
\hline
\end{tabular}

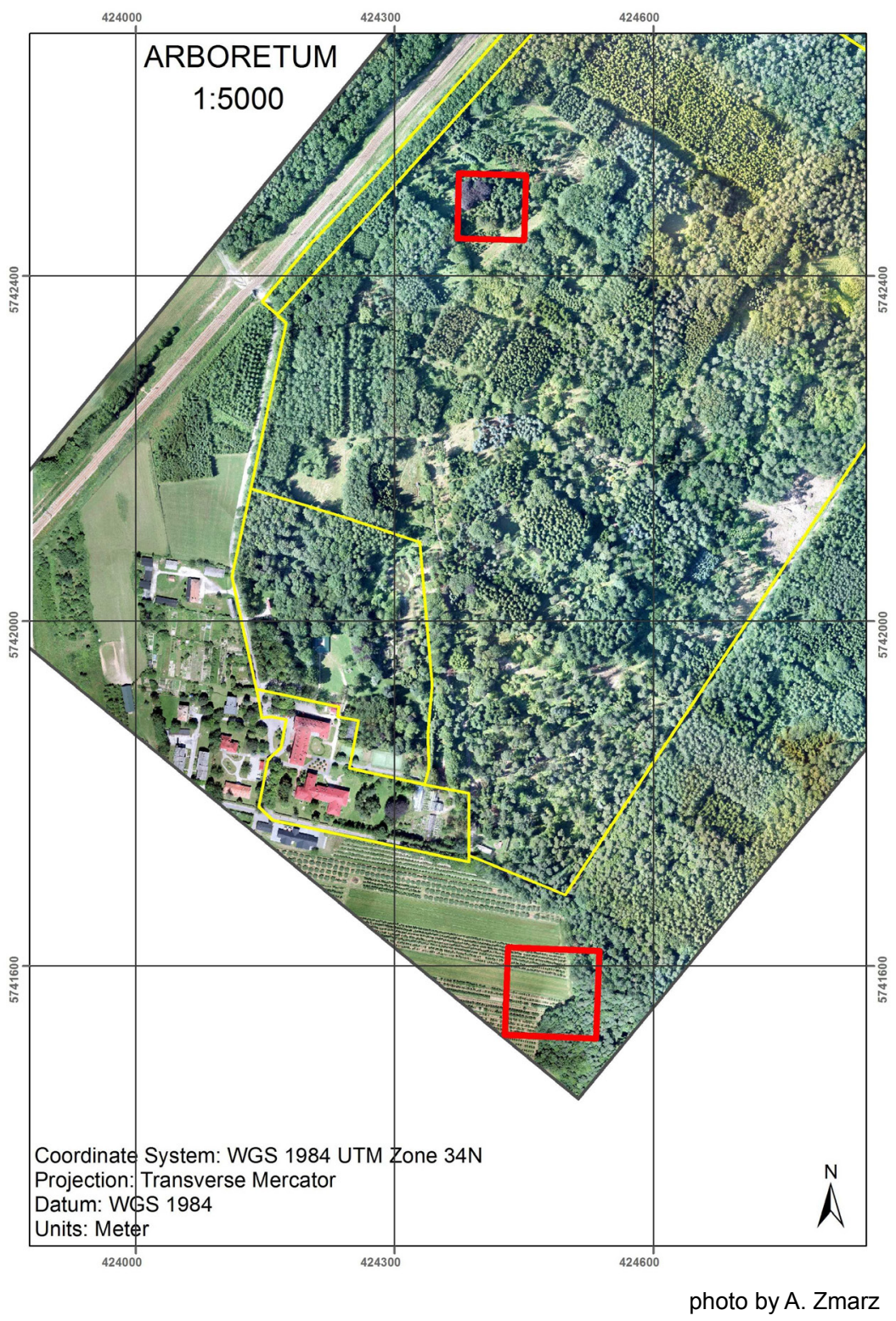

Figure 5. The Arboretum orthophoto made from images obtained by the Sigma DP2 camera. Flights over the Arboretum research area (60 ha) were performed using the UAV Mentor with MP2128. The red marked part of the orthophoto is shown in Fig. 6 and Fig. 7 


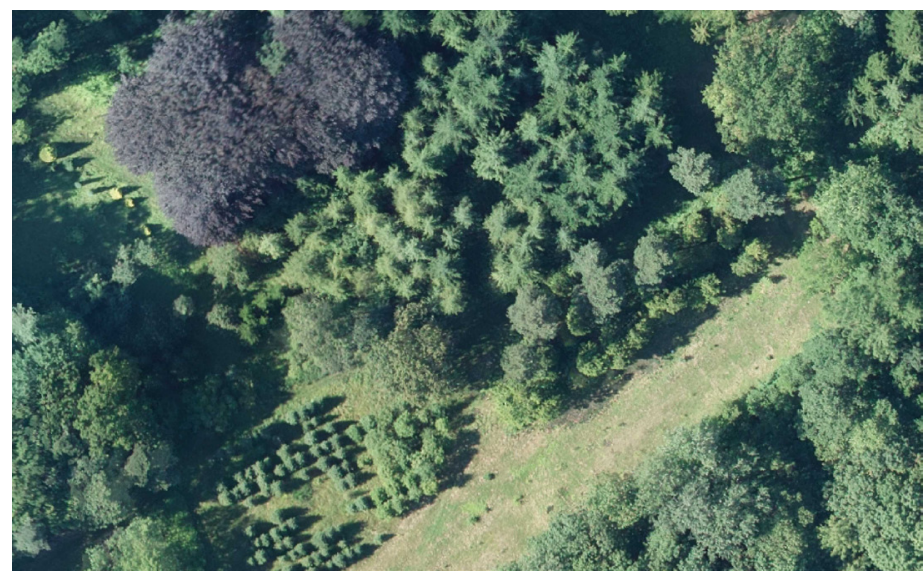

photo by A. Zmarz

Figure 6. A section of the orthophotos made from images obtained by the Sigma DP2 camera, recorded in the summer of 2010 (the image shows: 1 - Fagus sylvatica 'Atropunicea', 2 - Larix sibirica, 3 - Crown of oak (Quercus), 4 - Pinus cembra), the area of the scene is $135 \mathrm{~m} \times 82 \mathrm{~m}$

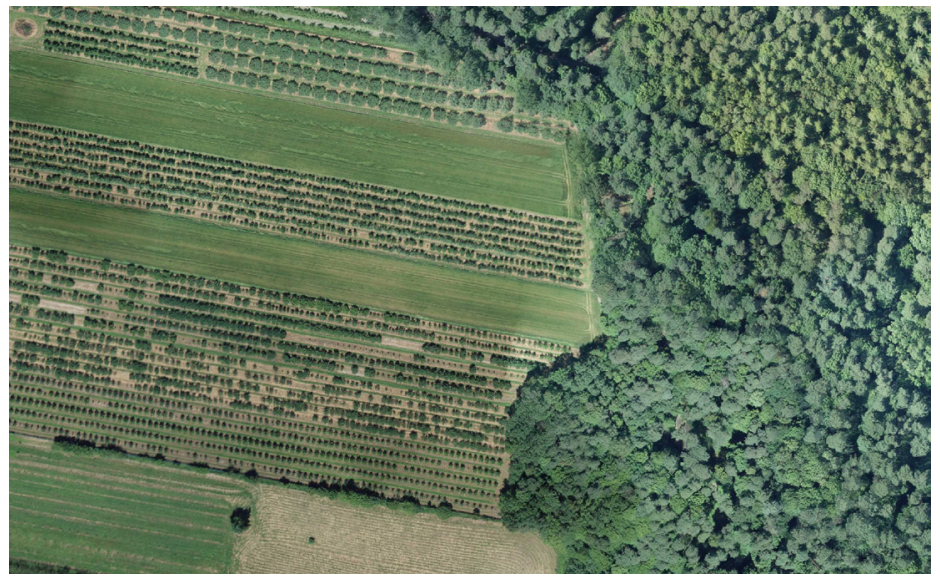

photo by A. Zmarz

Figure 7. A section of the orthophotos made from images obtained by the Sigma DP2 camera, recorded in the summer of 2010

When performing flights, the requirement that must be unconditionally met is continuous radio- and visualcommunication with the UAV throughout the flight (this is an operating principle to distinguish between different aerial objects when using a given airspace).

\section{Image data}

The basic outputs from the UAV operations are vertical and inclined aerial photos. Their spatial resolution is determined by the flight's altitude and the camera characteristics, and typically measures from a few to over a dozen centimetres.

The main products obtained from the photos taken by the UAVs are the orthophoto maps (Fig. 5, 6, 7, 8, 9, 10). These are compiled from a very large number of individual photos (e.g. for an area of about 300 ha, the number of photos may reach about one thousand) with EnsoMOSAIC software that uses image correlation algorithms supplemented by the GPS and heading data from the UAV and processes them into an orthophoto. In order to increase the orthophoto accuracy, ground control points (GCPs) are designated and measured. The points have been arranged in the field, to enable them to be located on images after the flight. The flights over Głuchów and the Arboretum areas were marked with white signs in the shape of a square with dimensions $30 \times 30 \mathrm{~cm}$ (the size of about a 2 pixel field), which allowed for the location of the selected point on the image. The GCPs were additional data that were used in the process of aerial triangulation. Some well-represented details may be identified on the images and later measured after the UAV operation has ended.

Another product obtained from the UAV's photos is the digital surface model (DSM). The DSM is created via the automatic correlation of images. The accuracy of DSM is determined by the number and accuracy of the measured reference points that make up the stereogram (a larger number of points established with high accuracy translates to higher accuracy of the DSM). Apart from the number and accuracy of the measured reference points, the DSM quality is also affected by the following factors: the scale of the photos (it is desirable to have a uniform scale, which requires a flight at the properly designated altitude), the accuracy of the correlation (influenced by the optical density of pixels), no shadows being cast on the photos (shadows on the photos or lack of objects on adjacent photos affect the number and accuracy of the reference points). Small format pictures (those obtained via UAVs) are usually taken using one image sensor, which registers RGB components. The accuracy of DSM using small-format pictures may be increased by attempts to change the size of the correlation search window and the correlation ratio. 


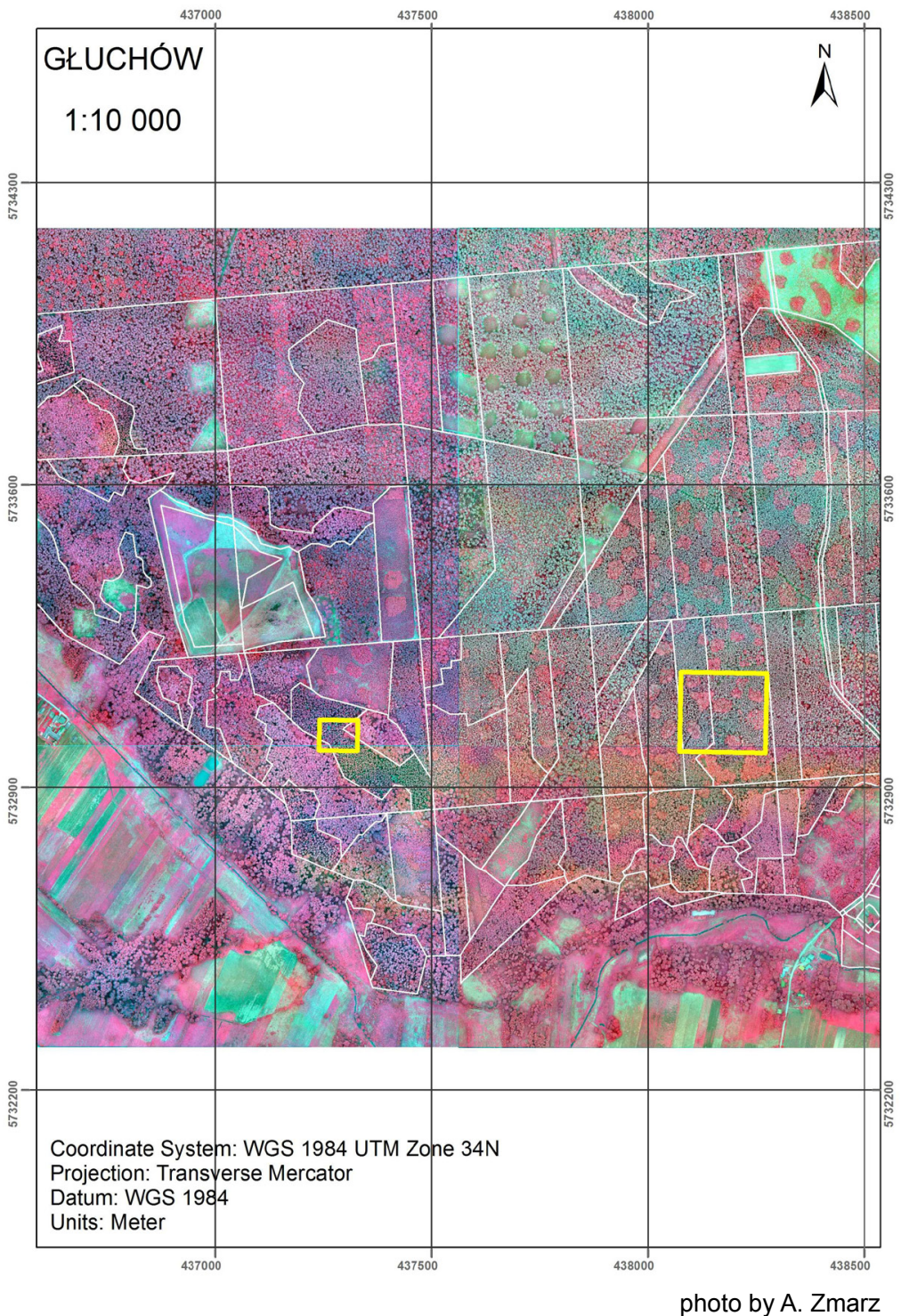

Figure 8. The CIR orthophotos made from images obtained by the Sigma DP2 camera. Images were recorded in the summer of 2010 for the Głuchów area (300 ha). Flights over the Głuchów area were performed using the UAV - AVI with MP2128. The yellow marked part of the orthophoto is shown in Fig. 9 and Fig.10

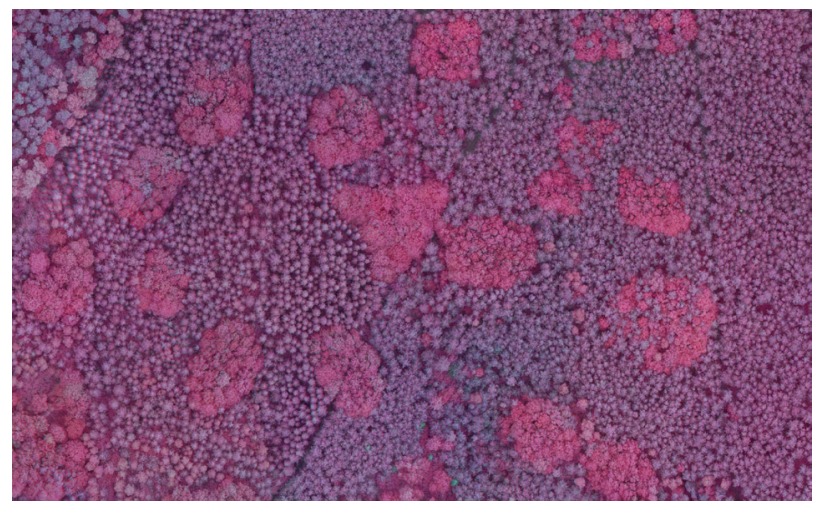

photo by A. Zmarz

Figure 9. A section of the CIR orthophotos made from images obtained by the Sigma DP2 camera. Images were recorded in the summer of 2010 for the Głuchów research area. Species of coniferous and deciduous trees are easily recognizable (the area of the scene is $365 \mathrm{~m} \times 220 \mathrm{~m}$ ) 


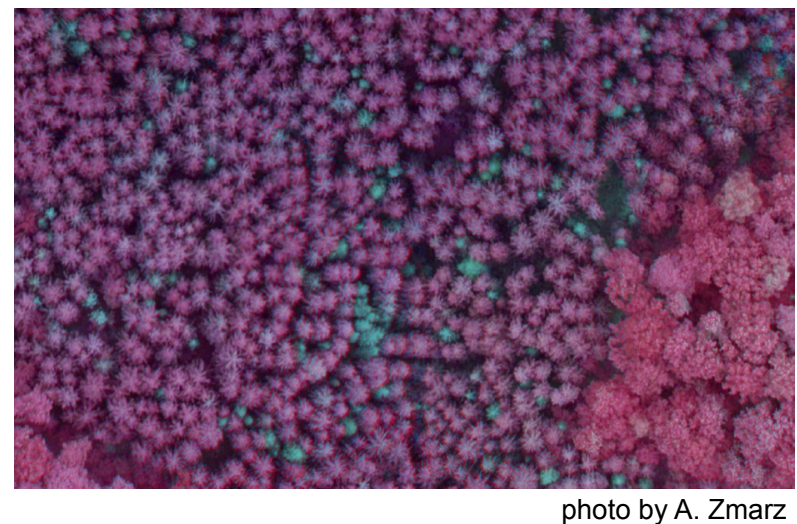

Figure 10. A section of the orthophotos made from images obtained by the Sigma DP2 camera. Images were recorded in the summer of 2010 for the Gtuchów research area. Dead spruces are visible (the area of the scene is $135 \mathrm{~m} \times 81 \mathrm{~m}$ )

The accuracy of an orthophoto depends on precision, with the GPS-measured and recorded coordinates of the single images and parameters characterizing the flight (maintenance of altitude, maintenance of flight path, angles of pitch and roll UAV). The latter depend on the proper integration of the autopilot with the aerodynamic shape of the aircraft (which directly translates into the proper execution of the flight route).

\section{Conclusions}

When taking aerial photographs with both large aeroplanes and UAVs, good weather is preferable, which translates into proper material for interpretation. Atmospheric conditions that impact the quality of the pictures are: good lighting, good visibility, no precipitation, good time of day, good season and low wind. When using UAV for photographic (photogrammetric) flights, it is important that the atmospheric conditions do not exceed the characteristics of the airframe. Flights may take place on both cloudless and fully-clouded days (when the flight takes place below the cloud cover, resulting in so-called no-shadow pictures). The deployment of UAVs for photogrammetric purposes is a prime example of the development of a new branch of technology which, as with all new developments, requires not only further technical and logistic improvements to achieve the required quality, but also requires all practical details to be established in order to meet the requirements of users (who are also in the process of learning this new technology) and the changing technical abilities of the equipment. Furthermore, all of these developments are taking place in a legal landscape that is unable to keep up with changing technology and its uses.

\section{References}

Aber, JS, Marzolff, I \& Ries, JB 2010, Small - format aerial photography, Elsevier.

Arjomandi, A, Agostino, S, Mammone, M, Nelson, M \& Zhou, T 2006, 'Classification of unmanned aerial vehicle', Report for Mechanical Engineering class, University of Adelaide, Adelaide, Australia.

Eisenbeiss, $\mathrm{H}$ 2008, 'The autonomous mini helicopter a powerful platform for mobile mapping', The International Archives of the Photogrammetry, Remote Sensing and Spatial Information Sciences, vol, XXXVII, part B1.

Goraj, Z, Kitmann, K, Voit-Nitschmann, R \& Szender, M 2010, 'Design and Integration of Flexi Bird - a low cost sub-scale research aircraft for safety and environmental issues', 27th International Congress of the Aeronautical Sciences, Nice, [September 2010].

Grenzdörffer, GJ, Engelb, A \& Teichert, B 2008, 'The photogrammetric potential of low-cost UAV's in forestry and agriculture', The International Archives of the Photogrammetry, Remote Sensing and Spatial Information Sciences, vol, XXXVII, part B1.
Koski, WR, Abgrall, P \& Yazvenko, SB 2010, 'An inventory and evaluation of unmanned aerial systems for offshore surveys of marine mammals', J Cetacean Res Manag, vol. 11, pp. 239-247.

Laliberte, AS, Herrick, JE, Rango, A \& Winters, C 2010, 'Acquisition, orthorectification, and object-based classification of unmanned aerial vehicle (UAV) imagery for rangeland monitoring', Photogrammetric Engineering \& Remote Sensing, vol. 76, no. 6, pp. 661-672 [June 2010].

Merino, L, Caballero, F, Martínez-de Dios, JR, Ferruz, J \& Ollero, A 2006, 'A cooperative perception system for multiple UAVs. Application to automatic detection of forest fires', This is a preprint of an article published in Journal of Field Robotics, vol. 23, no. 3-4, pp. 165-184.

Solb, S \& Storvold, R 2011, 'Sea ice mapping using unmanned aerial systems', AGU Fall Meeting, San Francisco, CA, USA, [5-9 December 2011].

Zmarz, A 2011, Application of UAV in forestry to acquire image data, Ph.D thesis, WULS - SGGW, Warszawa. 